Article

\title{
Effects on Motivation and Implicit Beliefs about Self Ability Using the Sports Education Model and the Traditional Style in Secondary Education
}

\author{
Lidia Hernández-Andreo, Alberto Gómez-Mármol * (iD and María Isabel Cifo-Izquierdo \\ Faculty of Education, University of Murcia, 30100 Espinardo, Spain; lidia.hernandez@um.es (L.H.-A.); \\ mariaisabel.cifo@um.es (M.I.C.-I.) \\ * Correspondence: alberto.gomez1@um.es
}

Received: 20 April 2020; Accepted: 7 May 2020; Published: 8 May 2020

\begin{abstract}
The methodology employed during physical education sessions can determine students' motivations and implicit beliefs about their own abilities. The aim of the present study was based on comparing the effects produced on motivation and implicit beliefs about self ability when implementing a Sports Education model and a traditional style. Ninety-three secondary education students participated in the study, with ages ranging from 13 to 15 (13.32 \pm 0.62$)$. A total of 54 students took part in the sessions designed according to the Sports Education model and 43 in those following a traditional style. At the beginning and the end of the didactic unit, each student was administered the questionnaire CMEF (Cuestionario de Motivación en Educación Física) for motivation in physical education and the questionnaire Conceptions of the Nature of Athletic Ability Questionnaire-2 (CNAAQ-2) for implicit beliefs about ability. Results showed significant differences for the Sports Education model in the dimensions of intrinsic motivation, identified regulation, introproyected regulation, and external regulation $(p<0.01)$. The Sports Education model is optimal to promote motivation; therefore, teachers should consider putting it into practice as a methodology to improve students' motivation profile.
\end{abstract}

Keywords: motivational profile; implicit belief; methodology; physical education

\section{Introduction}

In education, there is a lack of balance between the physical education curriculum and physical practices, which include repetitive content and knowledge based on memorizing. This predominates over more reflective learning, confirming the idea that these contents do not fit the expectations and needs of the students [1]. Teachers should create higher motivation for the practices in the physical education sessions with the aim of promoting learning, adherence, and future physical activities [2]. In this way, the main reason why students abandon physical activities is due to a lack of motivation towards them [3]. Besides, a variety of studies claim that motivation is a consequence of having high levels of implicit beliefs about ability [4-7]. Therefore, in the first place, to increase adherence to practicing physical activities regularly, the teacher has to ensure that students achieve effective and satisfactory implicit beliefs about their abilities [8,9]. The role the teacher plays is key to promoting motivation towards physical activities $[10,11]$ because a good motivational relationship between the teacher and the student has a positive effect on the student's academic performance [12]. Additionally, the type of methodology used should also be considered because it will also affect learning. For example, when variations of the Sports Education model (SEM) are made, better results are achieved than by varying traditional styles [13]. 


\subsection{Motivation for Learning}

Sporting activities in education centers promote student adherence and motivation towards physical practices during school hours [14] and can help promote personal values, such as respect, self-control, collaboration, and/or effort [15].

However, many children develop a sedentary lifestyle due to the excessive time they spend on their phones, playing games, or watching TV [16]. This might be caused by either a lack of interest in physical and/or sporting activities or because of a negative experience when doing physical activity [17]. In other words, a lack of interest and motivation could be caused by an intrinsic factor or could have an external origin when the experience of physical activities did not turn out as expected [18].

Moving forward, and in accordance with different investigations [19,20], the construct of motivation will be detailed; it is considered an abstract concept, multidisciplinary, and something that can be explained through human behavior. Weinberg and Gould [21] define motivation as a psychological element regulated by concepts such as (a) the direction, characterized by the objectives that someone chooses to obtain, (b) the intensity, meaning the degree of effort that is manifested to achieve them, and, finally, (c) the persistence and resilience that someone has to seek and obtain their aims. In a nutshell, motivation has a great influence on physical activities; this is due to the fact that most of the pedagogical models follow theories of implicit and explicit motivation [22]. This research is based on the Self-Determination Theory, formulated by Deci and Ryan [23], as a theoretical framework for motivation analysis. According to this theory, motivation can be understood as a continuum that encompasses those subjects who feel amotivated to those with an intrinsical motivation. Extrinsical motivation is placed between these two extremes. In turn, within extrinsical motivation, four profiles can be differentiated: external motivation, introproyected motivation, identified motivation, and integrated motivation. In the first case, external motivation, individuals engage in activities due to an external request, which leads to control and alienation feelings. In the second place, there is introproyected motivation, where tasks are done so as to avoid anxiety and to develop self-endorsement and pride. The third type is identified motivation, used by subjects who do activities even if they do not like them, but knowing that those activities will report them psychological and/or physiological benefits. Lastly, integrated motivation implies that individuals engage with the activities to practice them regularly, so, in the end, they get incorporated into their lifestyle.

The application of the self-determination theory on school contexts affirms that it is fundamental that the teacher encourages an environment of motivation because the teacher is considered a social component of great relevance who intervenes in motivation directly [10]. When the teacher shows a style that is controlling and dictatorial, students feel rejected and unmotivated [24]. Moreover, intrinsic motivation of students for physical activities in the school context influences the behavior outside the academic setting, and, besides, the teacher's support for autonomy behaviors also affects the degree of intrinsic motivation in students.

Therefore, the ways in which the teacher presents a task model, for example, by organizing the timetable of the sessions, or grouping and choosing the information to teach, are elements that favor an increase in motivation in general and in motivation to complete the task [25-27].

\subsection{Implicit Beliefs about Learning Ability}

In the field of physical activities, concrete proposals that study the implicit beliefs about ability that individuals have, and their influence on affective responses and motivation, are emerging. Li and Lee [28] define implicit beliefs about ability as what people think about the differences they perceive between ability and effort; if an ability is perceived as stable, it cannot be altered by effort, however, when the ability has been acquired through training, then it can be improved by making greater effort. Therefore, two types of beliefs about ability in the physical practice are differentiated: an incremental belief, based on the idea that the ability can be improved through learning and training; and an entity belief, which considers ability as biologically stable and not prone to change [29]. 
When analyzing the reasons why adolescents participate in physical activities, results show that entity beliefs anticipate positive orientation towards ego and incremental beliefs towards task [30]. Ommundsen [31], doing the same analysis with students aged between 15 and 16 in physical education sessions, affirmed that believing that ability is an innate and unalterable talent predicts orientation towards ego and that incremental belief does so towards the task. There is a positive correlation between incremental belief and orientation towards the task, and between entity belief and orientation towards ego. There is also a positive effect regarding incremental belief and orientation towards ego [31-33].

On the other hand, when considering implicit beliefs about ability and psychological agents, results claim that incremental belief, competency, and the relation perceived predict positively and significantly self-determined motivation. Nevertheless, entity beliefs about ability do so negatively and without drawing any relation to self-determined motivation and autonomy [34].

\subsection{Studying Implicit Beliefs about Ability through Motivational Profiles}

Currently, there are just a few studies that focus on investigating the relations between perceived motivational environments and implicit beliefs about ability. In the research by Wang and Biddle [35], students' motivational profiles were analyzed, differentiating a very motivated profile characterized by high levels of incremental beliefs about ability, perceived competency, low demotivation, and great participation in physical activities, and another profile with low motivation made up of older girls with a low level of orientation towards the task, of incremental beliefs about ability, perceived competency, and high levels of entity beliefs. Similar results were obtained when secondary education students were analyzed [36].

Moreover, Ommundsen [31] confirmed that a learning environment characterized by competitiveness in physical education lessons fosters entity beliefs. However, when in a physical education lesson, what stands out is work, progress, and help from the teacher, incremental beliefs are developed.

Li, Lee, and Solomon [37] conducted a study about object manipulation on university students. Results showed that girls who considered ability as something unalterable (entity belief) tended to manifest less intrinsic motivation, effort, enjoyment, and more anxiety and stress. On the other hand, girls who had an incremental belief about ability tended to feel more motivated intrinsically and made a bigger effort. It was also observed that participants who worked harder, regardless of their implicit belief about ability, felt more intrinsically motivated.

Currently, there are not many studies analyzing implicit beliefs about ability through an experimental design [38]. Nevertheless, the ones conducted consider motivation as a consequence of incremental beliefs [39].

Ommundsen, Haugem, and Lund [5] observed a positive correlation between self-regulating strategies, such as motivation and incremental beliefs, as well as between lack of ability and entity beliefs. It was also affirmed that entity beliefs predict unmotivation [4] and that a high perceived ability foretells intrinsic motivation [35,40].

Additionally, other studies have shown that when practicing physical activity, participants with high motivation also have high incremental beliefs about ability and low entity beliefs, whereas demotivated participants present high entity beliefs and low incremental beliefs $[35,40]$.

\subsection{Sports Education Model vs. Traditional Style: Effects on the Motivational Profile and Implicit Beliefs about Ability}

The absence of sporting activities in the physical education lessons that are realistic and make students feel successful sometimes originates from the appearance of alternative teaching models. As Siedentop, Hastie, and Van der Mars [41] pointed out, "Sport education is not a pie-in-the-sky" (p.1). One of the main problems in physical education lessons in the last decades consisted of the lack of development of a feeling of belonging in students because group practices are promoted 
only occasionally, whereas extracurricular activities did so more consistently [41]. This is due to a generalized traditional perspective characterized by controlled and decontextualized activities where students are in groups or teams on rare occasions. It is because of this that Siedentop, in the search for contextualization, created an enriching teaching model that provided physical education with real experiences.

When putting the SEM into practice in educational contexts, students value the teaching model positively, and it improves their perception of ability and enthusiasm for practicing physical activities [42]. It is also confirmed that students perceive a significant improvement in their ability and understanding of the sport practiced when using SEM [43]. On the contrary, a traditional style does not manage to increase the levels of physical activity practice in students, especially when compared to other pedagogical models with more responsibility transfer to students [44]. In the same line, when comparing SEM to a traditional style, the former shows more efficacy than the latter in developing motivation and positive attitudes because of the positive effects generated by social interactions and achievement goals [43]. However, teachers should be aware that the structural elements of the teaching model should foster a motivational climate [45].

Therefore, this research aimed to compare the effects produced on motivation and implicit beliefs about self ability when implementing a Sports Education model and a traditional style, because, in all the above, the research hypotheses predict that, unlike traditional teaching, the Sports Education model will raise motivation levels and incremental beliefs about ability.

\section{Materials and Methods}

\subsection{Participants}

A total of 97 students (58 males and 39 females) from four groups of the first year of secondary education participated in this study. Nevertheless, four participants were excluded for not completing all the items on the questionnaire or not doing it correctly. Then, the final sample was made up of 93 students ( 54 males and 39 females). Two groups (31 males and 21 females; $13.16 \pm 0.46$ years old) were taught according to the Sports Education model and the other two groups ( 23 males and 18 girls; $13.54 \pm 0.75$ years old) with traditional style. They all belonged to one educational center in the Murcia Region (Spain), and their ages ranged from 13 to 15 (13.32 \pm 0.62 ). Participants were chosen using non-probabilistic convenience sampling [46].

\subsection{Procedure}

The design of the study corresponds to the longitudinal type because it measured the changes in variables throughout the intervention [47]. Since participants were under-age, the main researcher first contacted the head of the school to present the investigation. Second, after having the head of the school's agreement to participate, an explanatory sheet with an informed consent was given to the Association of Parents, who also agreed. A didactic unit about alternative sports with twelve sessions was planned and implemented. Two sessions were taught per week, lasting a total of six weeks. Each session lasted $50 \mathrm{~min}$. The proposed didactic unit was presented to the group participants with a different methodological structure. The SEM was used in two groups and the traditional style in the remaining two groups.

On the first day of the intervention, participants were told the aim of the study, and instructions for the completion of the assessment tools were given. The purpose was to resolve any doubts about the process since they were going to be asked to assess their level of motivation and implicit beliefs about ability. The questionnaires were administered in the first session (pre-test) and at the end of the last session of the didactic unit (post-test). To complete both questionnaires, they were given $15 \mathrm{~min}$. Additionally, the answers were treated according to the ethical principles of anonymity and confidentiality prescribed in the Declaration of Helsinki. Participation in this research was completely voluntary and not linked, neither positively nor negatively, to the marks of any subject. 


\subsection{Instruments}

On the one hand, to ascertain the motivation of participants, the quantitative questionnaire of motivation towards physical education was used (CMEF) [48]. This questionnaire, headed with the line "I participate in physical education lessons ... " consisted of 20 items distributed into five factors: intrinsic motivation (4 items; e.g., "Because physical education is fun"), identified regulation (4 items; e.g., "Because this subject provides knowledge and abilities I consider important"), introprojected regulation (4 items; e.g., "Because I think it is necessary to feel good about myself"), external regulation (4 items; e.g., "To show the teacher and my classmates my interest in the subject"), and demotivation (4 items; e.g., "But really I feel I'm wasting my time with this subject"). The answers were marked according to a Likert scale from 1 (totally disagree) to 5 (totally agree). Internal consistency values (Cronbach's Alpha) for the factors were 0.74 for intrinsic motivation, 0.80 for identified regulation, 0.83 for introproyected regulation, 0.79 for external regulation, and 0.87 for demotivation.

On the other hand, to identify the participants' implicit beliefs about ability, the Spanish version of [37] Conceptions of the Nature of Athletic Ability Questionnaire-2 (CNAAQ-2) was used [4]. The questionnaire comprises two factors: incremental beliefs and entity beliefs. The instrument contains 12 items (six for each factor) with the headline "Your beliefs about your ability in sports are ... ". The answers were marked following a Likert scale from 1 (totally disagree) to 5 (totally agree). In the present study, values of 0.75 for the factor entity and 0.85 for the dimension incremental were obtained.

\subsection{Statistical Analysis}

The statistical analysis was done with the program IBM SPSS Statistics 24 . The dependent variables of the study were motivation and implicit beliefs about ability, whereas the type of methodology used (SEM or traditional style) was the independent variable. The data gathered was analyzed with descriptive statistics (mean and standard deviation), considering the pre-test and post-test measures of each variable in the study.

To clean the database, the Mahalanobis distance was calculated. The Shapiro-Wilk and chi-square were conducted to test normality in the data. Both showed nonparametric distributions. To know the impact of the intervention, the Wilcoxon test was performed on every variable in the study. To establish statistical significance, the value $p<0.05$ was used. Moreover, to know the effect size, Cohen's d coefficient was measured.

\section{Results}

Here, the results obtained after conducting the intervention with the application of SEM and traditional style are explained. Results are presented in two sections that show the effects related to each variable (motivation and implicit beliefs about ability).

\subsection{Effects of the Intervention on Motivation}

In Table 1, the values for the variable motivation obtained from the group where the didactic unit following SEM, and the group where a traditional style was used, are highlighted. 
Table 1. Effects of the intervention on motivation.

\begin{tabular}{ccccccccc}
\hline & \multicolumn{3}{c}{ Sports Education Model } & \multicolumn{3}{c}{ Traditional Style } \\
\cline { 2 - 9 } Motivation & Pre-Test & Post-Test & $p$ & $\begin{array}{c}\text { Cohen's } \\
\boldsymbol{d}\end{array}$ & Pre-Test & Post-Test & $\boldsymbol{p}$ & $\begin{array}{c}\text { Cohen's } \\
\boldsymbol{d}\end{array}$ \\
\hline Intrinsic & $4.18 \pm 0.80$ & $4.68 \pm 0.50$ & $0.000^{* *}$ & 0.749 & $4.08 \pm 0.78$ & $4.04 \pm 0.79$ & 0.892 & -0.051 \\
Identified & $3.85 \pm 1.03$ & $4.35 \pm 0.71$ & $0.000^{* *}$ & 0.565 & $3.87 \pm 0.67$ & $3.65 \pm 0.85$ & 0.188 & -0.287 \\
Introproyected & $3.24 \pm 1.01$ & $4.10 \pm 0.70$ & $0.000^{* *}$ & 0.990 & $3.10 \pm 0.87$ & $2.89 \pm 0.97$ & 0.153 & -0.228 \\
External & $3.46 \pm 0.99$ & $4.21 \pm 0.70$ & $0.000^{* *}$ & 0.875 & $3.22 \pm 0.92$ & $3.09 \pm 0.90$ & 0.473 & -0.143 \\
Demotivation & $1.57 \pm 0.94$ & $1.61 \pm 0.90$ & 0.786 & 0.043 & $2.10 \pm 1.07$ & $2.24 \pm 1.28$ & 0.790 & 0.119 \\
\hline \multicolumn{3}{c}{ Note: $* * 0.01}$.
\end{tabular}

When implementing SEM, statistically significant differences were observed for the dimensions intrinsic motivation, identified regulation, introprojected regulation, and external regulation, with a significance value of $(p<0.01)$. However, significant differences were not found for the dimension demotivation $(p=0.786)$. Participants valued with greater intensity the dimension intrinsic motivation both at the beginning $(M=4.18, S D=0.80)$ and at the end $(M=4.68, S D=0.50)$ of the didactic unit. Regarding the group taught with the traditional style, significant differences were not found for any of the dimensions in the variable motivation $(p>0.05)$. A decreasing tendency was observed in intrinsic, identified, introprojected, and external motivation, and an increase in the dimension demotivation.

\subsection{Effects of the Intervention on Implicit Beliefs about Ability}

In Table 2, the results for the variable implicit beliefs about ability obtained from the group where the didactic unit followed SEM, and the group where a traditional style was used, are displayed.

Table 2. Effects of the intervention on the variable implicit beliefs about ability.

\begin{tabular}{ccccccccc}
\hline \multirow{2}{*}{$\begin{array}{c}\text { Implicit } \\
\text { Beliefs }\end{array}$} & Pre-Test & Post-Test & $p$ & $\begin{array}{c}\text { Cohen's } \\
\boldsymbol{n}\end{array}$ & Pre-Test & Post-Test & $p$ & $\begin{array}{c}\text { Cohen's } \\
\boldsymbol{d}\end{array}$ \\
\hline $\begin{array}{c}\text { Incremental } \\
\text { Entity }\end{array}$ & $2.36 \pm 0.81$ & $2.23 \pm 0.87$ & 0.217 & -0.155 & $2.72 \pm 0.81$ & $2.60 \pm 0.83$ & 0.605 & -0.146 \\
\hline
\end{tabular}

Statistical differences were not found for the respective dimensions entity and incremental in either the SEM or in the traditional style $(p>0.05)$. The observed tendencies were that the incremental dimension was valued with higher marks and that the perception of implicit beliefs about ability decreased for both the entity and incremental dimensions.

\section{Discussion}

This study aimed to compare the effects of the application of two different methodologies, SEM and traditional style, on the motivation and implicit beliefs of ability in physical education sessions at the secondary education level.

Based on what is claimed by Self-determination Theory, the degree of satisfaction about basic psychological needs influences the appearance of motivation [26]. When SEM was applied, significant superior values were observed in the dimensions in the construct motivation: internal motivation, identified regulation, and introprojected regulation. Similarly, the literature previously reviewed shows that motivation can be developed thanks to the intervention of an SEM [42,43], by affirming that an increase in the participation of students in the practices promotes enthusiasm and motivation for these, as well as supporting authentic experiences.

Other studies confirm that in secondary education students, a high degree of compromise and participation in the roles of referee develop, and students show great enthusiasm for being a member of the same team during the season, establishing knowledge about technical and tactical contents 
specific to the sport $[49,50]$. These results could be justified because SEM fosters involvement in the task in small groups, where the student can make decisions and take responsibilities linked to the teaching and learning process while the teacher acts as a guide. It is worth mentioning that the student working in a team is given functions that manifest in complementary roles, favoring to a higher degree the level of compromise and incentivizing their practical involvement [41].

In this way, the SEM works as a tool to innovate in educational center sessions, supported by this knowledge about the characteristics that it provides to the development of motivation in the physical education sessions when compared to a traditional style [51]. However, a traditional style did not cause significant effects on the motivation of participants, and because of the relation between motivation and physical activities [17], its use is not suggested if the objective is to increase the levels of physical activity in participants [44]. In the same line, when comparing SEM to the traditional style, the former shows more efficacy than the latter in the motivational profile, as has happened in other studies [43,52]. Moreover, not only does SEM show more efficacy at a motivational level, it also improves the effects of learning with more consistency than the traditional style when modifications of the teaching model are made [13].

In the same vein, a traditional approach is characterized by the existence of a greater level of demotivation towards physical activities, where the environment favors students who show greater ability compared to their classmates [53]. In this study, that tendency was also observed.

Because of all these points, it is essential that teachers consider the structural elements of the teaching model to foster a motivational environment [45]. In this way, it is also ensured that students transfer knowledge to personal, social, and professional fields [2]. Thus, the research hypotheses were partially confirmed, since the Sports Education model did improve motivation but did not produce effects on incremental beliefs about ability. For its part, the traditional style did not show any effects neither on motivation nor on implicit beliefs.

One of the limitations of this research was that the randomization grouping of the students could not be respected (because the investigation was conducted in real practice contexts). Besides, the sample could also be expanded, not only in size but also to include different contexts. In this research, all the students were enrolled in only one secondary school, so the information extrapolation is a concern. Other limitations pointed to the duration of the research. Manzano, Valero, Conde, and Ming [54], as well as Martinek and Hellison [55], supported that to achieve consistent effects, longitudinal researches in school contexts should last 8 months at least. Finally, another limitation was not having included a re-test to assess the stability of the reported effects.

\section{Conclusions}

To resolve and address the objective established, comparing the effect of the application of two different methodologies, SEM and traditional style, in the promotion of motivation and implicit beliefs about ability in physical education sessions in secondary education, the following conclusions are presented:

A statistically significant promotion of motivation in the application of SEM compared to the traditional style has been confirmed.

It has not been shown that the application of either SEM or a traditional style improves the perception of implicit beliefs about ability in participants. In this sense, one practical application for physical education teachers emerges. It is proposed to develop researches that hybridize SEM with the attitudinal teaching style [56]. This emerging teaching style fosters that any student, regardless of their motor ability level, achieves feelings of success in physical education lessons. Consequently, the hybridization of SEM and attitudinal teaching style could design a methodology capable of reporting positive effects on implicit beliefs about ability, especially on incremental factors since it considers that ability could be improved with effort. 
Author Contributions: Conceptualization, L.H.-A. and M.I.C.-I.; methodology, L.H.-A.; formal analysis, A.G.-M.; investigation, L.H.-A., A.G.-M., and M.I.C.-I.; resources, L.H.-A. and A.G.-M.; data curation, A.G.-M.; writing-original draft preparation, L.H.-A., A.G.-M., and M.I.C.-I.; writing-review and editing, M.I.C.-I. All authors have read and agreed to the published version of the manuscript.

Funding: This research received no external funding.

Conflicts of Interest: The authors declare no conflict of interest.

\section{References}

1. González-Cutre, D.; Sicilia, A.; Moreno-Murcia, J.A. A quasi-experimental study of the effects of task-involving motivational climate in physical education classes. Rev. Educ. 2011, 356, 677-700.

2. Ruiz, P.A.; Cifo, M.I. Analysis of valence, arousal and dominance during the practice of body expression in high school. Emás Revista Digital EF 2020, 11, 9-21.

3. D'Anna, C.; Forte, P.; Gomez, F. Physical education status in European school's curriculum, extension of educational offer and planning. J. Hof. Hum. Sport Exerc. 2019, 14, 805-817.

4. Biddle, S.J.H.; Wang, C.K.J.; Chatzisarantis, N.L.D.; Spray, C.M. Motivation for physical activity in young people: Entity and incremental beliefs about athletic ability. J. Sports Sci. 2003, 21, 973-989. [CrossRef]

5. Ommundsen, Y.; Haugen, R.; Lund, T. Academic self-concept, implicit theories of ability, and self-regulation strategies. Scand. J. Educ. Res. 2005, 49, 461-474. [CrossRef]

6. Wang, C.K.J.; Biddle, S.J.H. Intrinsic motivation towards sports in Singaporean students: The role of sport ability beliefs. J. Health Psychol. 2003, 8, 515-523. [CrossRef]

7. Wang, C.K.J.; Liu, W.C. Promoting enjoyment in girls' physical education: The impact of goals, beliefs, and self-determination. Eur. Phys. Educ. Rev. 2007, 13, 145-164. [CrossRef]

8. Ryan, R.M.; Deci, E.L. Selfregulation and the problem of human autonomy: Does psychology need choice, self-determination, and will? J. Personal. 2006, 74, 1557-1585. [CrossRef]

9. Trigueros, R.; Aguilar-Parra, J.M.; Cangas, A.J.; López-Liria, R.; Álvarez, J.F. Influence of physical education teachers on motivation, embarraccment and the intention of being physically active during adolescence. Int. J. Environ. Res. Public Health 2019, 16, 2295. [CrossRef]

10. Albarracín, A.; Moreno-Murcia, J.A.; Beltrán, V.J. The current situation of physical education according to teachers: A qualitative study with teacherse from the region of murcia. Cult. Sci. Sport 2014, 9, 225-234. [CrossRef]

11. Ulstad, S.O.; Halvari, H.; Deci, E. The role of students and teachers? Ratings of autonomous motivation in a self-determination theory model predicting participation in physical education. Scand. J. Educ. Res. 2019, 63, 1086-1101. [CrossRef]

12. Abos, A.; Haerens, L.; Sevil-Serrano, J.; Morbée, S.; Julián, J.A.; García-González, L. Does the level of motivation of physical education teachers matter in terms of job satisfaction and emotional exhaustion? A person-centered examination base don self-determination theory. Int. J. Environ. Res. Public Health 2019, 16, 2839. [CrossRef]

13. Pan, Y.-H.; Huang, C.-H.; Lee, I.-S.; Hsu, W.-T. Comparison of learning effects of merging TPSR respectively with sport education and traditional teaching model in high school physical education classes. Sustainability 2019, 11, 2057. [CrossRef]

14. Trigueros, R.; Navarro, N. The influence of the teacher on the motivation, learning strategies, critical thinking and academic performance of high school students in physical education. Psychol. Soc. Educ. 2019, 11, 137-150.

15. Sánchez-Oliva, D.; Viladrich, C.; Amado, D.; González-Ponce, I.; García-Calvo, T. Predicción de los comportamientos positivos en educación física: Una perspectiva desde la teoría de la autodeterminación. Rev. Psicodidáctica 2014, 19, 387-406.

16. De la Villa-Moral, M.; Suárez, C. Risk factors in the problematic use of Internet and phone in Spanish adolescents. Rev. Iberoam. Psicol. Salud 2016, 7, 69-79.

17. Beltrán-Carrillo, V.J.; Devís-Devís, J.; Peiró-Velert, C.; Brown, D.H. When physical activity participation promotes inactivity: Negative experiences of Spanish adolescents in physical education and sport. Youth Soc. 2012, 44, 3-27. [CrossRef] 
18. De Meester, A.; Maes, J.; Stodden, D.; Cardon, G.; Goodway, J.; Lenoir, M.; Haerens, L. Identifying profiles of actual and perceived motor competence among adolescents: Associations with motivation, physical activity and sports participation. J. Sport Sci. 2016, 34, 2027-2037. [CrossRef]

19. Cera, E.; Almagro, B.J.; Conde, C.; Sáenz-López, P. Emotional intelligence and motivation in secondary physical education. Retos. Nuevas Tend. Educ. Física Deporte Recreación 2015, 27, 8-13.

20. De Meyer, J.; Soenens, B.; Vansteenkiste, M.; Aelterman, N.; Van Petegem, S.; Haerens, L. Do students with different motives for physical education respond diferently to autonomy-supportive and controlling teaching? Psychol. Sport Exerc. 2016, 22, 72-82. [CrossRef]

21. Weinberg, R.S.; Gould, D. Foundations of Sport and Exercise Psychology; Human Kinetics: Champaign, IL, USA, 2018.

22. Stavrou, N.; Psychountaki, M.; Georgiadis, E.; Karteroliotis, K.; Zervas, Y. Flow theory-goal orientation theory: Positive experiencia is related to athlete's goal orientation. Front. Psychol. 2015, 6, 1499. [CrossRef] [PubMed]

23. Deci, E.L.; Ryan, R.M. The what and why of goal pursuits: Human needs and the self-determinatio of behavior. Psychol. Inq. 2000, 11, 227-268. [CrossRef]

24. Ling, J.; Soos, I.; Dizmatsek, I.; Ojelabi, A.; Simonek, A.; Boros-Balint, I.; Szabo, P.; Szabo, A.; Hamar, P. Perceived autonomy support and motivation in young people: A comparative investigation of physical education and leisure-time in four countries. Eur. J. Psychol. 2019, 15, 509-530.

25. Moreno-Murcia, J.A.; Cervelló, E.M.; González-Cutre, D. Self-determined motivation and dispositional flow in sport. An. Psicol. 2006, 22, 310-317.

26. Ryan, R.M.; Deci, E.L. Overview of self-determination theory: An organismic dialectical perspective. In Handbook of Selfdetermination Research; Deci, E.L., Ryan, R.M., Eds.; University of Rochester Press: Rochester, NY, USA, 2002; pp. 3-33.

27. Almagro, B.J.; Sáenz-López, P.; González-Cutre, D.; Moreno-Murcia, J.A. Perceived motivational cllimate, psychological needs and intrinsic motivation as predictors of sport commitment in adolescent atheletes. RICYDE 2011, 7, 250-265.

28. Li, W.; Lee, A. A review of conceptions of ability and related motivational constructs in achievement motivation. Quest 2004, 56, 439-461. [CrossRef]

29. De Castella, K.; Byrne, D. My intelligence may be more malleable than yours: The revised implicit theories of intelligence (self-theory) scale is a better predictor of achievement, motivation and student disengagement. Eur. J. Psychol. Educ. 2015, 3, 245-267. [CrossRef]

30. Biddle, S.J.H.; Soos, I.; Chatzisarantis, N.L.D. Predicting physical activity intentions using goal perspectives and self-determination theory approaches. Eur. Psychol. 1999, 4, 83-89. [CrossRef]

31. Ommundsen, Y. Pupils' affective responses in physical education classes: The association of implicit theories of the nature of ability and achievement goals. Eur. Phys. Educ. Rev. 2001, 7, 219-242. [CrossRef]

32. Cervelló, E.; González-Cutre, D.; Moreno-Murcia, J.A.; Iglesias, D. The role of the motivation in the prediction of procedimental knowledge in basketball players. Univ. Psychol. 2016, 15, 1-13.

33. González-Cutre, D.; Sicilia, A.; Moreno-Murcia, J.A. The social-cognitive model of achievement motivation in physical education. Psicothema 2008, 20, 642-651.

34. Lee, Y.; Seo, E. Trajectories of implicit and their relations to scholastic aptitude: A mediational role of achievement goals. Contemp. Educ. Psychol. 2019, 59, 101800. [CrossRef]

35. Wang, C.K.J.; Biddle, S.J.H. Young people's motivational profiles in physical activity: A cluster analysis. J. Sport Exerc. Psychol. 2001, 23, 1-22. [CrossRef]

36. Wang, C.K.J.; Chatzisarantis, N.L.D.; Spray, C.M.; Biddle, S.J.H. Achievement goal profiles in school physical education: Differences in self-determination, sport ability beliefs, and physical activity. Br. J. Educ. Psychol. 2002, 72, 433-445. [CrossRef]

37. Li, W.; Lee, A.M.; Solmon, M.A. Relationships among dispositional ability conceptions, intrinsic motivation, perceived competence, experience, persistence, and performance. J. Teach. Phys. Educ. 2005, 24, 51-65. [CrossRef]

38. Moreno-Murcia, J.A.; Gea-Escámez, A.; Corbí, M. Prediction of children's physical activity perception based on the belief of the parents' ability. Cuad. Psicol. Deporte 2018, 18, 1-11.

39. Moreno-Murcia, J.A.; Cervelló, E.; Martínez, C.; Huéscar, E.; Sáenz-López, P. Conceptions of ability and self-determined motivation in young Spanish athletes. Psicol. Reflex. Crit. 2014, 27, 515-521. [CrossRef] 
40. Chian, L.K.Z.; Wang, C.K.J. Motivational profiles of junior college athletes: A cluster analysis. J. Appl. Sport Psychol. 2008, 20, 137-156. [CrossRef]

41. Siedentop, D.; Hastie, P.A.; Van der Mars, H. Complete Guide to Sport Education; Human Kinetics: Champaign, IL, USA, 2004.

42. Calderón, A.; Hastie, P.A.; Martínez de Ojeda, D. Learning to teach sport education: Initial experience in elementary education. CCD 2010, 5, 169-180. [CrossRef]

43. Méndez-Giménez, A.; Fernández-Río, J.; Méndez-Alonso, D. Sport education versus traditional model: Effects on motivation and sportmanship. Rev. Int. Med. Cienc. Act. Física Deporte 2015, 15, 449-466.

44. Benítez, J. Teaching style influence in physical activity patterns. Rev. Int. Deportes Colect. 2017, 32, 5-7.

45. Sinelnikov, O.A.; Hastie, P.A. A motivational analysis of a season of sport education. Phys. Educ. Sport Pedagog. 2010, 15, 55-69. [CrossRef]

46. Otzen, T.; Manterola, C. Sampling techniques on a population study. Int. J. Morphol. 2017, 35, $227-232$. [CrossRef]

47. Delgado, M.; Llorca, J. Longitudinal studies: Concept and particularities. Rev. Española Salud Pública 2004, 78, 141-148.

48. Sánchez-Oliva, D.; Leo, F.M.; Amado, D.; González-Ponce, I.; García-Calvo, T. Develop of a questionnaire to assess the motivation in physical education. Rev. Iberoam. Psicol. Ejerc. Deporte 2012, 7, 227-250.

49. Hastie, P.A.; Sinelkinov, O.A. Russian students' participation in and perceptions of a season of sport education. Eur. Phys. Educ. Rev. 2006, 12, 131-151. [CrossRef]

50. Farias, C.; Valerio, C.; Mesquita, I. Sport Education as a curriculum approach to student learning of invasion games: Effects on game performance and game involvement. J. Sports Sci. Med. 2018, 17, 56-65.

51. Calderón, A.; Martínez de Ojeda, D.; Méndez-Giménez, A. In-service education and teachers' perception about key competences development with sport education. Retos. Nuevas Tend. Educ. Física Deporte Recreación 2013, 23, 33-38.

52. García-López, L.M.; Gutiérrez, D.; González-Víllora, S.; Valero, A. Changes in empathy, assertiveness and social relations due to the implementation of th sport education model. Rev. Psicol. Deporte 2012, 21, 321-330.

53. Valero, A.; Delgado, M.; Conde, J.L. Motivation towards athletics practice in primary education depending on two different teachin/learning proposals. Rev. Psicol. Deporte 2009, 18, 123-136.

54. Manzano, D.; Valero, A.; Conde, A.; Ming, C. Applying the personal and social responsibility model-based program: Differences according to gender between basic psychological needs, motivation, life satisfaction and intention to be physically active. Int. J. Environ. Res. Public Health 2019, 16, 1-10.

55. Martinek, T.; Hellison, D. Teaching personal and social responsibility: Past, present and future. J. Phys. Educ. Recreat. Danc. 2016, 87, 9-13. [CrossRef]

56. Pérez-Pueyo, A. The attitudinal style in physical education: Evolution in the past 20 years. Retos. Nuevas Tend. Educ. Física Deporte Recreación 2016, 29, 207-215.

(C) 2020 by the authors. Licensee MDPI, Basel, Switzerland. This article is an open access article distributed under the terms and conditions of the Creative Commons Attribution (CC BY) license (http://creativecommons.org/licenses/by/4.0/). 